\title{
Effects of NO/cGMP inhibitors in a rat model of anaphylactoid shock
}

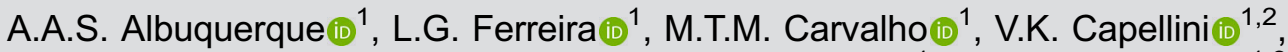 \\ P.R.B. Evora (ii) ${ }^{1}$, and A.C. Celotto ii ${ }^{1,3}$ \\ ${ }^{1}$ Departamento de Cirurgia e Anatomia, Faculdade de Medicina de Ribeirão Preto, Universidade de São Paulo, \\ Ribeirão Preto, SP, Brasil \\ ${ }^{2}$ Departamento de Biociências, Instituto de Saúde e Sociedade, Campus Baixada Santista, Universidade Federal de São Paulo, \\ Santos, SP, Brasil \\ ${ }^{3}$ Faculdade de Ciências da Saúde de Barretos Dr. Paulo Prata, Barretos, SP, Brasil
}

\begin{abstract}
Anaphylactic shock can be defined as an acute syndrome, and it is the most severe clinical manifestation of allergic diseases. Anaphylactoid reactions are similar to anaphylactic events but differ in the pathophysiological mechanism. Nitric oxide (NO) inhibitors during anaphylaxis suggest that NO might decrease the signs and symptoms of anaphylaxis but exacerbate associated vasodilation. Therefore, blocking the effects of NO on vascular smooth muscle by inhibiting the guanylate cyclase (GC) would be a reasonable strategy. This study aimed to investigate the effects of NO/cGMP pathway inhibitors methylene blue (MB), $\mathrm{N}^{\omega}$-nitro-L-arginine methyl ester hydrochloride (L-NAME), and indigo carmine (IC) in shock induced by compound $48 / 80(\mathrm{C} 48 / 80)$ in rats. The effect was assessed by invasive blood pressure measurement. Shock was initiated by $\mathrm{C} 48 / 80$ intravenous bolus injection $5 \mathrm{~min}$ before (prophylactic) or after (treatment) the administration of the inhibitors $\mathrm{MB}$ ( $3 \mathrm{mg} / \mathrm{kg}$ ), L-NAME (1 mg/kg), and IC (3 mg/kg). Of the groups that received drugs as prophylaxis for shock, only the IC group did not present the final systolic blood pressure (SBP) better than the C48/80 group. Regarding shock treatment with the drugs tested, all groups had the final SBP similar to the C48/80group. Altogether, our results suggested that inhibition of GC and NO synthase in NO production pathway was not sufficient to revert hypotension or significantly improve survival.
\end{abstract}

Key words: Endothelial cells; Allergy; Rodent; Nitric oxide; Anaphylaxis

\section{Introduction}

Anaphylactic shock can currently be defined as an acute syndrome, the most severe clinical manifestation of allergic diseases. Potentially fatal, it is a type I hypersensitivity reaction against specific antigens, leading to the formation of antibodies (1). The reaction requires sensitization to a particular substance which, on contact, produces immunoglobulin $E(\lg E)$ against the immunogen. When a new exposure occurs, the immune system responds immediately to mast cell degranulation (2-4).

Anaphylactoid reactions are like anaphylactic manifestations but differ in the pathophysiological mechanism. The pathogenesis of anaphylaxis typically involves IgEdependent events, and the anaphylactoid responses include lgE-independent results that otherwise are clinically indistinguishable $(1,5)$.

Anaphylactic and severe anaphylactoid reactions present the same clinical course and treatment $(6,7)$. Mast cell degranulation releases inflammatory immune mediators that cause hypotension and shock.
It is known that nitric oxide (NO), an endogenous vasodilator, is associated with anaphylaxis. Moreover, experimental studies have shown that the inhibition of nitric oxide synthase (NOS) by L-arginine analogues reverses the hypotension caused by anaphylactic shock $(8,9)$.

Histamine binding to $\mathrm{H} 1$ receptors during anaphylaxis also stimulates endothelial cells to convert the amino acid L-arginine into NO that activates guanylate cyclase (GC), leading to vasodilation and production of cyclic guanosine monophosphate (cGMP). Increased NO production decreases venous return, thus contributing to the vasodilation that occurs during anaphylaxis. NO inhibitors during anaphylaxis also promote bronchospasm, suggesting that NO might reduce the signs and symptoms of anaphylaxis but exacerbate associated vasodilation (10-12). Thus, blocking the effects of $\mathrm{NO}$ on vascular smooth muscle would inhibit GC, inhibiting vasodilation, being a reasonable strategy for anaphylaxis treatment.

Correspondence: P.R.B. Evora: <prbevora@gmail.com>

Received July 3, 2019 | Accepted December 4, 2019 
Compound 48/80 (C48/80) is known to be a potent hypotensive agent and inducer of degranulation, responsible for releasing about $90 \%$ of histamine and other chemical mediators associated with symptoms of anaphylaxis and activation of mast cells $(13,14)$. It has been used experimentally as a direct and convenient reagent to investigate the mechanisms of allergy and anaphylaxis, and, therefore, it has no clinical relevance, only experimental (15-17).

This study aimed to investigate the effects of $\mathrm{NO} /$ cGMP pathway inhibitors [methylene blue (MB), $\mathrm{N}^{\omega}$-nitroL-arginine methyl ester hydrochloride (L-NAME), and indigo carmine (IC)] in the treatment of induced shock by $\mathrm{C} 48 / 80$ in rats. The effects were assessed by observation of clinical signs, invasive blood pressure measurement, and the survival of animals in each experimental group (one of the main aims of the research).

\section{Material and Methods}

\section{Ethics statement and animals}

The animal procedures, as well as the experimental protocols of this study, were approved by the Ethics Committee on Animal Use (CEUA) of the University of São Paulo at Ribeirão Preto Medical School (protocol 190/210), according to the Ethical Principles in Animal Experimentation of the Brazilian College of Animal Experimentation (COBEA).

Male Wistar rats 70-90 days of age (300-350 g) were housed under standard laboratory conditions (12-h light/ dark cycle at $22^{\circ} \mathrm{C}$ ), with free access to food and water.

\section{Drugs}

Urethane, C48/80, MB, L-NAME, and IC were from Sigma Chemical Company (USA) and all the drugs were prepared with distilled water.

\section{Experimental design and treatment protocol}

The animals were anesthetized with urethane $(2 \mathrm{mg} /$ $\mathrm{kg}, \mathrm{ip}$ ) and maintained on spontaneous ventilation. After complete anesthesia, the inguinal region was cleaned and hair was removed. An incision was made and the femoral artery and vein were isolated and cannulated $(24 \mathrm{G} \times$ 0.75", Angiocath (Becton \& Dickinson, Brazil). The femoral artery and vein were used for continuous measurement of systolic (SBP) and diastolic (DBP) blood pressure and drug administration, respectively. Blood pressure monitoring was performed using the MP System $100 \mathrm{~A}$ (Biopac System, Inc., USA) connected to a PC Gateway (Gateway, USA) with Windows XP operating system (Microsoft, USA) that can collect, analyze, store, and retrieve biophysical data. The vascular catheters were connected to pressure transducers, and these were connected to the continuous registration recorder MP System $100 \mathrm{~A}$.
Shock was induced with C48/80 (3 mg/kg) by intravenous bolus injection, $5 \mathrm{~min}$ before (prophylactic) or after (treatment) the administration of the inhibitors [MB (3 $\mathrm{mg} / \mathrm{kg})$, L-NAME (1 mg/kg), IC (3 mg/kg)]. The doses for the drugs were chosen based on literature data $(9,18-20)$.

Animals were randomly assigned into eleven groups ( $n=6$ in each group): control, C48/80, MB, MB + C48/ 80, C48/80 + MB, L-NAME, L-NAME + C48/80, C48/80 + L-NAME, IC, IC + C48/80, and C48/80 + IC. SBP and survival were analyzed over $60 \mathrm{~min}$. SBP was examined every $10 \mathrm{~min}$ for $60 \mathrm{~min}$ or until death of the animal, whichever occurred sooner.

All animals that had a survival time of $60 \mathrm{~min}$ had blood samples collected from the femoral artery and placed in heparinized tubes (Eppendorf do Brasil, Brazil). Plasma was obtained by centrifugation at $2,500 \mathrm{~g}$ for $10 \mathrm{~min}$ at $4^{\circ} \mathrm{C}$ and immediately immersed in liquid nitrogen and freezerstored $\left(-70^{\circ} \mathrm{C}\right)$ to determine the nitrate/nitrite ratio. Plasma indirect dosages were performed by determining serum levels of nitrite and nitrate using the Sievers 280i NO Analyzer (Sievers, USA).

\section{Statistical analysis}

Two-way ANOVA followed by Bonferroni post-test was used for statistical analysis of SBP. Moreover, for the analysis of the indirect measurements of the plasma NO, one-way ANOVA was used while for survival studies Kaplan-Meier method was chosen. The software used was GraphPad Prism version 5.0 (GraphPad Software Corporation, USA). The level of significance adopted was $\mathrm{P}<0.05$.

\section{Results}

As described in the literature (21), characteristics of anaphylactic shock hypotension were observed in the first minute after injection of the compound.

C48/80 was efficient in shock induction because the rats presented hypotension, characteristic clinical signs such as cyanotic ears, paws, and tongue, and respiratory distress. The SBP and DBP decreased soon after C48/80 was administered and remained stable until the end of the experiment (Figure 1A and Table 1). Also, compared to the control group and basal measurement, it promoted a significant reduction in final systolic and diastolic blood pressures (Figure 1B and Table 1). Animal survival was $50 \%$ in the first hour after C48/80 infusion (Figure 1C).

Regarding survival, the group that received only $\mathrm{MB}$ or IC maintained the SBP (Figure 2A) and had $100 \%$ survival (Figure 2B), similar to the control group, during the $60 \mathrm{~min}$ that they were monitored. The L-NAME group remained with significantly higher SBP than the control group (Figure 2A), with $100 \%$ survival during the same time (Figure 2B). 

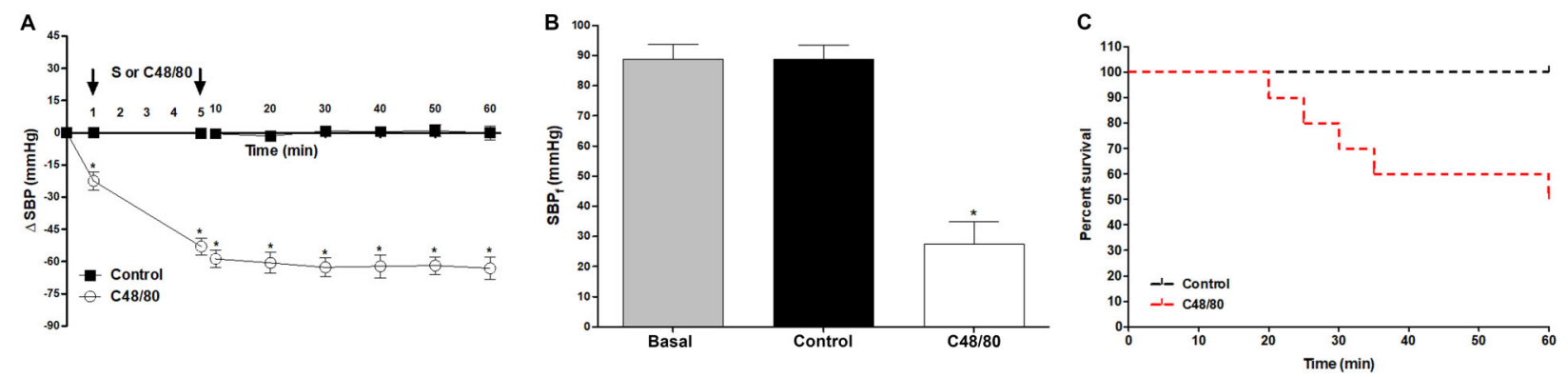

Figure 1. A, Systolic blood pressure (SBP), B, final systolic blood pressure $\left(\mathrm{SBP}_{\mathrm{f}}\right)$, and $\mathbf{C}$, survival measurements of the control group and the group that received only $\mathrm{C} 48 / 80$. Data are reported as mean $\pm \mathrm{SE}$. ${ }^{*} \mathrm{P}<0.001 \mathrm{C} 48 / 80$ compared to control (A: two-way repeated-measures ANOVA and Bonferroni post-test; B: one-way ANOVA and Bonferroni post-test and C: Kaplan-Meier; $\mathrm{n}=6$ ). S: saline.

Table 1. Initial and final systolic (SBP) and diastolic (DBP) blood pressures of the groups studied.

\begin{tabular}{|c|c|c|}
\hline Groups & Initial & Final $(60 \mathrm{~min})$ \\
\hline \multicolumn{3}{|l|}{ Control } \\
\hline SBP & $88.85 \pm 5.02$ & $88.78 \pm 4.66$ \\
\hline DBP & $62.02 \pm 4.38$ & $62.10 \pm 3.39$ \\
\hline \multicolumn{3}{|l|}{$\mathrm{C} 48 / 80$} \\
\hline SBP & $89.75 \pm 5.1$ & $27.60 \pm 7.39$ \\
\hline DBP & $69.18 \pm 6.2$ & $25.29 \pm 7.07$ \\
\hline \multicolumn{3}{|l|}{ MB } \\
\hline SBP & $89.85 \pm 5.03$ & $87.24 \pm 3.63$ \\
\hline DBP & $64.78 \pm 3.78$ & $63.50 \pm 2.78$ \\
\hline \multicolumn{3}{|c|}{$M B+C 48 / 80$} \\
\hline SBP & $92.18 \pm 5.48$ & $37.73 \pm 7.30$ \\
\hline DBP & $69.15 \pm 4.06$ & $30.98 \pm 5.47$ \\
\hline \multicolumn{3}{|c|}{$\mathrm{C} 48 / 80+\mathrm{MB}$} \\
\hline SBP & $86.67 \pm 2.64$ & $28.62 \pm 2.62$ \\
\hline DBP & $62.01 \pm 2.87$ & $21.28 \pm 1.65$ \\
\hline \multicolumn{3}{|l|}{ L-NAME } \\
\hline SBP & $83.59 \pm 5.23$ & $110.27 \pm 4.07$ \\
\hline DBP & $55.11 \pm 4.21$ & $88.60 \pm 3.39$ \\
\hline \multicolumn{3}{|c|}{ L-NAME + C48/80 } \\
\hline SBP & $102.68 \pm 6.27$ & $43.63 \pm 8.08$ \\
\hline DBP & $76.15 \pm 7.32$ & $37.14 \pm 6.68$ \\
\hline \multicolumn{3}{|c|}{ C48/80 + L-NAME } \\
\hline SBP & $89.12 \pm 7.07$ & $29.67 \pm 5.89$ \\
\hline DBP & $64.60 \pm 5.25$ & $24.63 \pm 5.31$ \\
\hline \multicolumn{3}{|l|}{ IC } \\
\hline SBP & $97.11 \pm 1.88$ & $94.25 \pm 5.34$ \\
\hline DBP & $68.67 \pm 2.25$ & $67.14 \pm 4.68$ \\
\hline \multicolumn{3}{|c|}{ IC $+C 48 / 80$} \\
\hline SBP & $101.32 \pm 7.35$ & $23.70 \pm 3.21$ \\
\hline DBP & $71.55 \pm 6.97$ & $20.44 \pm 2.60$ \\
\hline \multicolumn{3}{|c|}{$C 48 / 80+I C$} \\
\hline SBP & $103.98 \pm 6.51$ & $30.24 \pm 5.16$ \\
\hline DBP & $76.14 \pm 6.06$ & $23.99 \pm 3.74$ \\
\hline
\end{tabular}

Data are reported as mean $\pm \mathrm{SE}$. MB: methylene blue; L-NAME: $\mathrm{N}^{\omega}$-nitro-Larginine methyl ester hydrochloride; IC: indigo carmine. 


\section{Methylene blue treatment}

The group that was given $M B$ to prevent shock caused by $\mathrm{C} 48 / 80(\mathrm{MB}+\mathrm{C} 48 / 80)$ presented better SBP (Figure $3 \mathrm{~A})$ and slightly higher final $\operatorname{SBP}\left(\mathrm{SBP}_{\mathrm{f}}\right)(37 \pm 7 \mathrm{mmHg})$ compared to the group that received only the $C 48 / 80$ (Figure $3 B$ ). However, in the MB treatment group $(C 48 / 80+M B)$, the SBP decreased after the compound infusion, and after the MB injection, a further decrease in SBP was observed
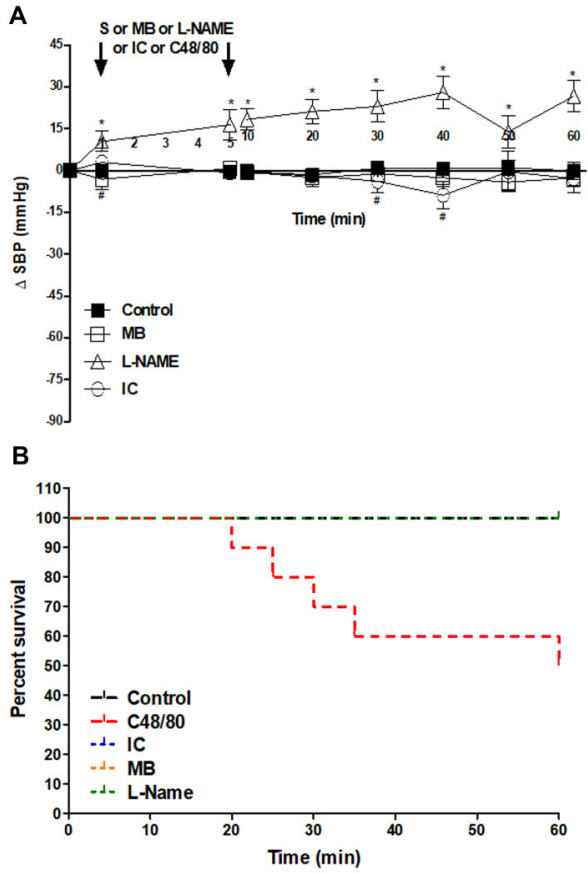

Figure 2. A, Systolic blood pressure (SBP) and B, survival evaluation of the control group and drug groups (MB, L-NAME, and IC). Data are reported as mean $\pm S E$. ${ }^{*} P<0.001 \mathrm{~L}-\mathrm{NAME}$ vs control; ${ }^{\#} \mathrm{P}<0.05$ IC vs control. (A: two-way repeated-measures ANOVA and Bonferroni post-test; B: Kaplan-Meier; $n=6$ ). S: saline; MB: methylene blue; L-NAME: $\mathrm{N}^{\omega}$-nitro-L-arginine methyl ester hydrochloride; IC: indigo carmine; S: saline.
(Figure $3 \mathrm{~A}$ ). Finally, the $\mathrm{SBP}_{\mathrm{f}}$ was similar to the $\mathrm{C} 48 / 80$ group (28 $\pm 2 \mathrm{mmHg}$ ) (Figure $3 \mathrm{~B}$ ). Survival was prolonged with $\mathrm{MB}$ pre-treatment, although it did not change the final survival. $\mathrm{MB}$ administration after $\mathrm{C} 48 / 80$ reduced survival time (60 to $45 \mathrm{~min}$ ) (Figure $3 \mathrm{C}$ ).

\section{L-NAME treatment}

The SBP of the group in which L-NAME was used as prevention (L-NAME + C48/80) immediately increased when the drug was injected, but decreased significantly after induced shock, having a small improvement compared to the $\mathrm{C} 48 / 80$ group after $40 \mathrm{~min}$ (Figure $4 \mathrm{~A})\left(\mathrm{SBP}_{\mathrm{f}}\right.$ $43 \pm 8 \mathrm{mmHg}$ ) (Figure 4B) and survival did not differ from C48/80 (Figure $4 \mathrm{C}$ ). When animals received L-NAME as treatment for shock (C48/80 + L-NAME), SBP showed a decrease when the compound was injected and no improvement with L-NAME. However, the treated group kept a better pressure than the compound group (Figure 4A). Moreover, the $\mathrm{SBP}_{\mathrm{f}}$ was similar to the $\mathrm{C} 48 / 80$ group $(29 \pm 5 \mathrm{mmHg})$ (Figure 4B). Survival was reduced with L-NAME after C48/80 (Figure 4C).

\section{IC treatment}

IC administered for shock prevention (IC + C48/80) promoted a significant increase in SBP immediately after application (1 $\mathrm{min})$, which remained until the 5 th $\mathrm{min}$ when the C48/80 was injected. Then, the SBP decreased significantly and was maintained lower than the C48/80 group until the end of the experiment (Figure 5A) with a $\mathrm{SBP}_{\mathrm{f}}$ of $23 \pm 3 \mathrm{mmHg}$ (Figure $5 \mathrm{~B}$ ) and survival was a little worse than $\mathrm{C} 48 / 80$ group (Figure $5 \mathrm{C}$ ).

As shock treatment $(C 48 / 80+I C)$, the dye did not alleviate the decrease in SBP, which remained lower than the $\mathrm{C} 48 / 80$ group (Figure $5 \mathrm{~A}$ ), ending the experiment with an $\mathrm{SBP}_{\mathrm{f}}$ of $30 \pm 5 \mathrm{mmHg}$ (Figure $5 \mathrm{~B}$ ) and survival of $30 \%$ in 60 min (Figure 5C).

\section{NO levels}

Analysis of the groups that received the drugs tested and that survived until the end of the study showed that
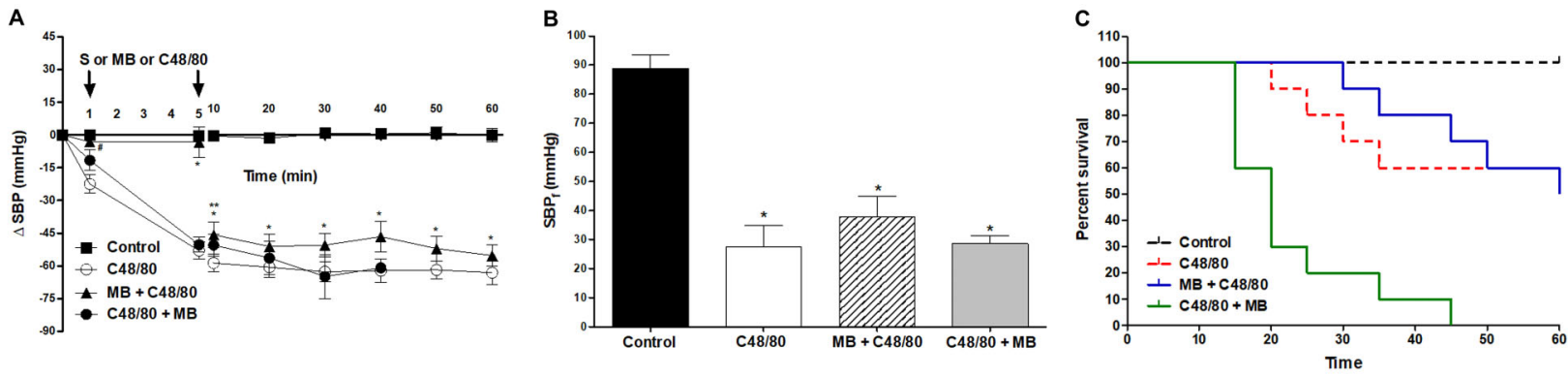

Figure 3. A, Systolic blood pressure (SBP), B, final systolic blood pressure $\left(\mathrm{SBP}_{\mathrm{f}}\right)$, and $\mathbf{C}$, survival measurements of rats that received $\mathrm{C} 48 / 80$ and/or MB (Kaplan-Meier, $\mathrm{n}=6$ ). Data are reported as mean $\pm \mathrm{SE}$. A: ${ }^{*} \mathrm{P}<0.001 \mathrm{MB}+\mathrm{C} 48 / 80$ vs control; ${ }^{* *} \mathrm{P}<0.001 \mathrm{MB}+\mathrm{C} 48 /$ 80 vs $\mathrm{C} 48 / 80$; ${ }^{\#} \mathrm{P}<0.01 \mathrm{MB}+\mathrm{C} 48 / 80$ vs $\mathrm{C} 48 / 80$ (two-way repeated-measures $\mathrm{ANOVA}$ and Bonferroni post-test); $\mathbf{B}$ : ${ }^{*} \mathrm{P}<0.001$ compared to control (one-way ANOVA and Bonferroni post-test). MB: methylene blue; S: saline. 

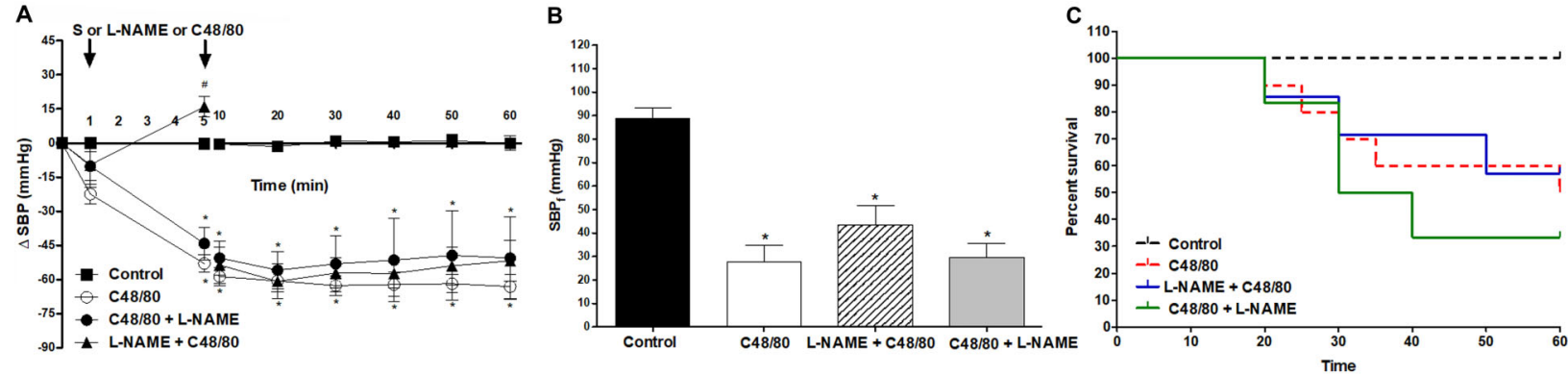

Figure 4. A, Systolic blood pressure (SBP), B, final systolic blood pressure $\left(\mathrm{SBP}_{\mathrm{f}}\right)$, and $\mathbf{C}$, survival measurements of rats that received $\mathrm{C} 48 / 80$ and/or L-NAME (Kaplan-Meier, $\mathrm{n}=6$ ). Data are reported as mean $\pm \mathrm{SE}$. A: ${ }^{*} \mathrm{P}<0.001 \mathrm{C} 48 / 80, \mathrm{C} 48 / 80+\mathrm{L}-\mathrm{NAME}, \mathrm{L}-\mathrm{NAME}+\mathrm{C} 48 /$ 80 vs control; ${ }^{\#} \mathrm{P}<0.001 \mathrm{~L}-\mathrm{NAME}+\mathrm{C} 48 / 80$ vs $\mathrm{C} 48 / 80$ (two-way repeated-measures ANOVA and Bonferroni post-test); $\mathrm{B}$ : ${ }^{*} \mathrm{P}<0.001$ compared to control (one-way ANOVA and Bonferroni post-test). L-NAME: $\mathrm{N}^{\omega}$-nitro-L-arginine methyl ester hydrochloride; S: saline.
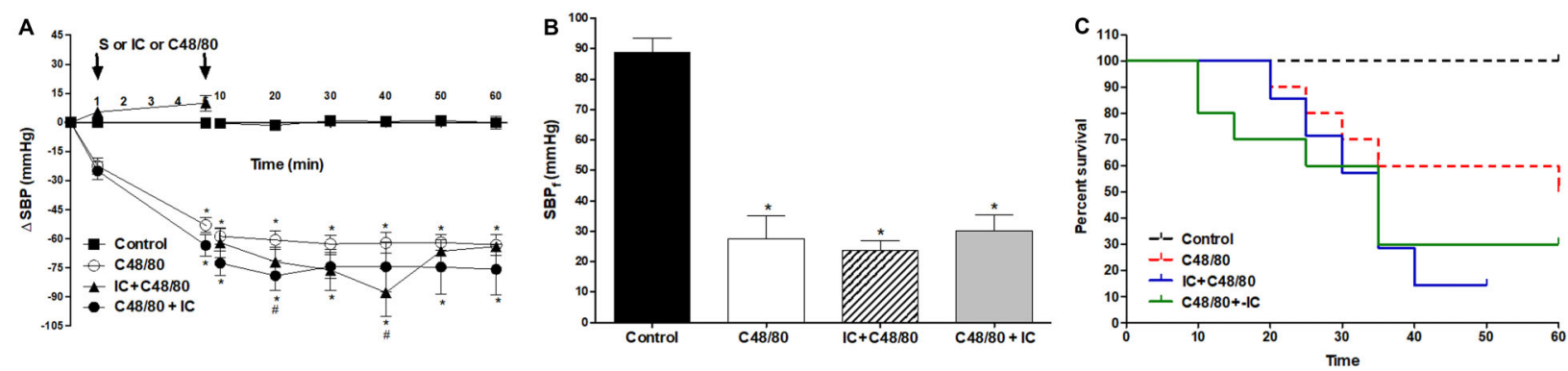

Figure 5. A, Systolic blood pressure (SBP), B, final systolic blood pressure $\left(\mathrm{SBP}_{\mathrm{f}}\right)$, and $\mathbf{C}$, survival measurements (Kaplan-Meier; $\mathrm{n}=6$ ) of rats that received C48/80 and/or IC. Data are reported as mean $\pm \mathrm{SE}$. A: ${ }^{*} \mathrm{P}<0.001 \mathrm{C} 48 / 80, \mathrm{C} 48 / 80+\mathrm{IC}$, IC + C48/80 vs control; ${ }^{\#} \mathrm{P}<0.05$ IC + C48/80, C48/80 + IC vs C48/80 (two-way repeated-measures ANOVA and Bonferroni post-test); $\mathrm{B}$ : ${ }^{*} \mathrm{P}<0.001$ compared to control (one-way ANOVA and Bonferroni post-test). IC: indigo carmine; S: saline.

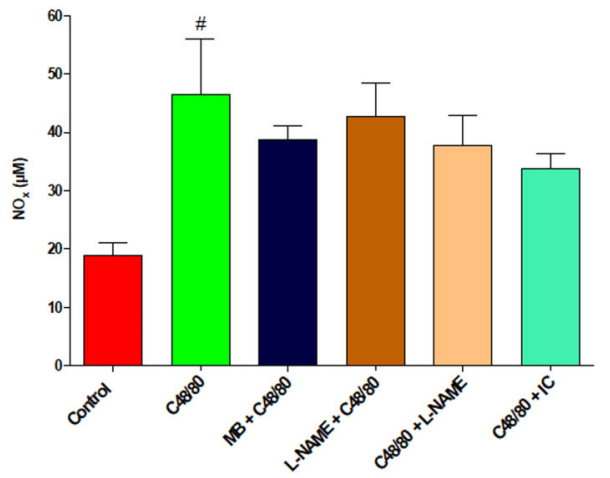

Figure 6. Plasma nitric oxide (NO) analysis of all groups. Data are reported as mean $\pm \mathrm{SE}{ }^{\#} \mathrm{P}<0.01$ compared to control (one-way ANOVA and Bonferroni post-test). MB: methylene blue; L-NAME: $\mathrm{N}^{\omega}$-nitro-L-arginine methyl ester hydrochloride; IC: indigo carmine.

plasma NO dosages between the groups were similar, with a statistically significant difference only between C48/ 80 group and the control group (Figure 6).

\section{Discussion}

C48/80 has been used to produce experimental anaphylactic shock, because this compound is known to increase histamine release from plasma or tissue $(22,23)$ and an additional nitric oxide release from endothelial cells (24). Our data showed that this compound was effective in inducing anaphylactic shock in rats since blood pressure decreased after C48/80 administration. In addition, the majority of the animals exposed to $C 48 / 80$ presented cyanosis on ears, paws, and tongue, and respiratory distress. At the end of $60 \mathrm{~min}$, all animals that received C48/80 showed a sudden drop in both systolic and diastolic pressure, practically equaling these pressures. The pulse pressure of almost zero justified the symptoms presented by the animals.

C48/80 acts by increasing the permeability of the lipid bilayer membrane of mast cells promoting disruption of the cell membrane, and mast cell degranulation by changing the free cytoplasmic calcium concentration, releasing mediators of anaphylaxis. Histamine, the most common mediator, connects to receptors on the endothelial cell 
membrane and triggers the synthesis of $\mathrm{NO}$, resulting in vasorelaxation. However, some studies have shown that the C48/80 and other polybasic compounds are apparently capable of directly activating $G$ proteins $(25,26)$.

As observed in this work, other authors also demonstrated the efficiency of C48/80 in inducing anaphylactoid shock in mice $(14,27,28)$, rats $(15,29)$, guinea pigs $(30)$, rabbits (18), and pigs (9). The ability of C48/80 to promote a direct release of nitric oxide from endothelial cells was confirmed by a significant increase in nitric oxide plasma levels. Unfortunately, none of the treatments employed was able to reduce nitric oxide levels, including L-NAME, probably because the release was high, considering the stimulus from histamine plus the direct effect on endothelium.

In some studies, the compound caused $100 \%$ mortality in animals (31), probably due to the potent hypotensive effect, mast cell degranulation, and nitric oxide release. It is also responsible for the release of about $90 \%$ of histamine and other chemical mediators as serotonin, associated with anaphylaxis symptoms $(15,22)$.

One of the main aims of this study was to analyze animal survival with substances used as treatment and prevention of anaphylactoid shock. To avoid or minimize the hypotension caused by $\mathrm{C} 48 / 80$, we decided to use the NO pathway inhibitors, because it is the main final mediator of the vasodilation pathway.

MB was chosen as a non-selective inhibitor of GC. Therefore, it was expected that when the action of this enzyme was blocked, cGMP would not increase, thus inhibiting vasodilatation. However, the group that received the prophylactic MB did not show a significant stabilization of blood pressure. Furthermore, treated animals showed worse hypotension and increased mortality, compared to the $C 48 / 80$ group. These findings corroborate the results of Takano et al. (27) who used MB as prophylaxis to shock induced by the compound in mice. On the other hand, it differs from the results reported by Buzato et al. (18) as they observed a significant recovery of blood pressure in rabbits receiving $\mathrm{MB}$ as a treatment to shock.

The prophylactic use of MB has been shown to be effective in improving survival of rabbits after C48/80induced shock (18). However, in this experimental model, prophylactic MB did not improve survival from C48/80 shock.

The survival evaluation results in an experiment with rabbits were more faithful to the effects observed in humans who had anaphylactic shock and were treated with MB (32) than with the experimental mouse model. These results showed that there may have been a blockage of GC when $\mathrm{MB}$ was used as prevention, resulting in enough decrease in vasodilation to increase survival by $70 \%$ compared to the treated group.

The clinical use of MB for the treatment of anaphylactic shock shows excellent results in more than 20 cases. However, anaphylactic shock is a medical emergency and there is no evidence that MB was the primary choice, and thus it is challenging to design a study that would be in line with ethical principles. In these studies, MB therapy was only started after treatment with conventional drugs like vasopressors, corticosteroids, antihistamines, and fluids was carried out and did not work. In some cases, hypotension reversal occurred immediately after the first dose, but in others, a second dose or even a continuous infusion of $M B$ was required.

In this study, L-NAME was also not effective in recovering hypotension caused by shock when used as both prevention and treatment. SBP remained close to the values of the C48/80 group, showing a slight increase after $20 \mathrm{~min}$. However, the use of L-NAME caused an improvement in the shock group, possibly because the endothelial nitric oxide synthase (eNOS) was blocked by the inhibition of NO production, with a consequent SBP increase. Differing from these findings, L-NAME attenuated anaphylactic hypotension in mice (33), reduced vasodilation induced by histamine in the mesenteric region and upper limbs in cats, and reduced vasodilation of venules in pigs and cerebral arteries in monkeys (34). The isolated L-NAME infusion can reduce cardiac output, promoting bronchoconstriction and increasing anaphylaxis mortality. The use of NOS inhibitors in the treatment of anaphylactic shock is still questionable.

The treated rats had a higher mortality than the C48/80 group and the group that received the substance as prophylaxis improved survival around $25 \%$. Cauwels et al. (35) observed a similar result when using mice sensitized with bovine serum albumin. The vasodilation can be explained by its dependence on eNOS, which maintains hypotension and causes circulatory shock and mortality (27).

IC, besides acting by blocking the endotheliumdependent vasodilation, also affects peripheral alpha constrictors $(36,37)$. IC when used as a blue dye for urologic and gynecologic procedures to identify ureteral patency occasionally causes side effects that include hypertension. This effect is associated with a vasoconstriction effect (38). However, few cases of severe hypotension after IC injection have been reported in the literature $(39,40)$.

IC, contrary to expectations, was not effective in improving the survival of animals either as prophylaxis or as treatment. Considering the ambiguous effect of IC on blood pressure, at this time, it is difficult to understand the mechanism involved in the present results.

In the adopted animal model of anaphylactoid shock, severe hypotension associated with impairment of tissue perfusion and high mortality was observed. This condition was probably mediated by increased plasma NO. However, the blockade in the NO/cGMP pathway with MB, L-NAME, or IC as treatment did not improve the low blood pressure or mortality caused by $\mathrm{C} 48 / 80$. On the other hand, survival time increased when the substances were 
applied prophylactically. It is possible that in this anaphylactic model the shock was too severe, hampering the prevention only by NO/cGMP pathway blockade.

\section{Acknowledgments}

This study received financial support from National Council of Scientific and Technological Development

\section{References}

1. Marx J, Walls R, Hockberger R. Rosen's Emergency Medicine. Concepts and Clinical Practice E-Book.Elsevier Health Sciences; 2013.

2. LouzadaJrP, Oliveira FR, Sarti W. Anafilaxia e reações anafilactóides. Medicina 2003; 36: 399-403.

3. Palmiere C. Anaphylactic and anaphylactoid reactions. J Forensic Leg Med 2016; 44: 35-36, doi: 10.1016/j.jlm. 2016.08.004.

4. Male DK, Brostoff J, Roth DB, Roitt IM. Immunology. 7th ed: Mosby; 2006. p 552.

5. Lagopoulos V, Gigi E. Anaphylactic and anaphylactoid reactions during the perioperative period. Hippokratia 2011; 15: 138-140.

6. Tupper J, Visser S. Anaphylaxis: a review and update. Can Fam Physician 2010; 56: 1009-1011.

7. Lopes RA, Pivato LS. Hipersensibilidade imediata: uma revisão sobre anafilaxia. Revista Saúde e Pesquisa 2012; 5: $147-160$.

8. Albuquerque AA, Margarido EA, Menardi AC, Scorzoni AF, Celotto AC, Rodrigues AJ, et al. Methylene blue to treat protamine-induced anaphylaxis reactions. An experimental study in pigs. Braz J Cardiovasc Surg 2016; 31: 226-231.

9. Menardi AC, Capellini VK, Celotto AC, Albuquerque AA, Viaro $F$, Vicente $W V$, et al. Methylene blue administration in the compound 48/80-induced anaphylactic shock: hemodynamic study in pigs. Acta Cir Bras 2011; 26: 481-489, doi: 10.1590/S0102-86502011000600013.

10. Kemp SF, Lockey RF. Anaphylaxis: a review of causes and mechanisms. J Allergy Clin Immunol 2002; 110: 341-348, doi: 10.1067/mai.2002.126811.

11. Mitsuhata $H$, Shimizu R, Yokoyama MM. Role of nitric oxide in anaphylactic shock. J Clin Immunol 1995; 15: 277-283, doi: 10.1007/BF01541317.

12. Rosic M, Parodi O, Jakovljevic V, Colic M, Zivkovic V, Jokovic V, et al. Glucagon effects on 3H-histamine uptake by the isolated guinea-pig heart during anaphylaxis. Biomed Res Int 2014; 2014: 782709, doi: 10.1155/2014/782709.

13. Nishikawa H, Kitani S. Tea catechins have dual effect on mast cell degranulation induced by compound $48 / 80$. Int Immunopharmacol 2008; 8: 1207-1215, doi: 10.1016/j.intimp. 2008.04.010.

14. Yoon TJ, Lee SJ, Kim EY, Cho EH, Kang TB, Yu KW, et al. Inhibitory effect of chaga mushroom extract on compound 48/80-induced anaphylactic shock and $\operatorname{lgE}$ production in mice. Int Immunopharmacol 2013; 15: 666-670, doi: 10. 1016/j.intimp.2013.03.015.

15. Choi $\mathrm{YH}$, Yan $\mathrm{GH}$, Chai $\mathrm{OH}$, Song $\mathrm{CH}$. Inhibitory effects of curcumin on passive cutaneous anaphylactoid response and compound 48/80-induced mast cell activation.
(CNPq), Coordination of Improvement of Higher Academic Personnel (CAPES), Foundation for Support of Education, Foundation for Research and Service of the Clinical Hospital at Ribeirão Preto Medical School, University of São Paulo (FAEPA).

Anat Cell Biol 2010; 43: 36-43, doi: 10.5115/acb.2010.43. 1.36 .

16. Xu Y, Guo N, Dou D, Ran X, Ma X, Kuang H. Proteomics Study on nonallergic hypersensitivity induced by compound 4880 and ovalbumin. PLoS One 2016; 11: e0148262, doi: 10.1371/journal.pone.0148262.

17. Yi JM, Hong SH, Lee HJ, Won JH, Kim JM, Jeong DM, et al. Ixeris dentata green sap inhibits both compound 48/80induced anaphylaxis-like response and IgE-mediated anaphylactic response in murine model. Biol Pharm Bull 2002; 25: 5-9, doi: 10.1248/bpb.25.5.

18. Buzato MA, Viaro F, Piccinato CE, Evora PR. The use of methylene blue in the treatment of anaphylactic shock induced by compound 48/80: experimental studies in rabbits. Shock 2005; 23: 582-587.

19. Evora PR, Ribeiro PJ, de Andrade JC. Methylene blue administration in SIRS after cardiac operations. Ann Thorac Surg 1997; 63: 1212-1213, doi: 10.1016/S0003-4975(97) 00198-7.

20. Gomes JC, Antonio A. Effects of compound $48 / 80$ on the guinea-pig isolated heart: a comparison with the in vitro cardiac anaphylaxis. Pharmacol Res Commun 1981; 13: 873-890, doi: 10.1016/S0031-6989(81)80047-1.

21. Dewachter P, Jouan-Hureaux V, Lartaud I, Bello G, de Talance $\mathrm{N}$, Longrois $\mathrm{D}$, et al. Comparison of arginine vasopressin, terlipressin, or epinephrine to correct hypotension in a model of anaphylactic shock in anesthetized brown Norway rats. Anesthesiology 2006; 104: 734-741, doi: 10.1097/00000542-200604000-00018.

22. Paton WD. Compound 48/80: a potent histamine liberator. Br J Pharmacol Chemother 1951; 6: 499-508, doi: 10.1111/ j.1476-5381.1951.tb00661.x.

23. Ohta $\mathrm{Y}$, Yashiro K, Ohashi K, Horikoshi $\mathrm{Y}$, Kusumoto $\mathrm{C}$, Matsura T. Compound 48/80, a mast cell degranulator, causes oxidative damage by enhancing vitamin $\mathrm{C}$ synthesis via reduced glutathione depletion and lipid peroxidation through neutrophil infiltration in rat livers. $J$ Clin Biochem Nutr 2017; 60: 187-198, doi: 10.3164/jcbn.16-89.

24. Viaro F, Celotto AC, Capellini VK, Baldo CF, Rodrigues AJ, Vicente WV, et al. Compound 48/80 induces endotheliumdependent and histamine release-independent relaxation in rabbit aorta. Nitric Oxide 2008; 18: 87-92, doi: 10.1016/ j.niox.2007.11.004.

25. Tomita U, Inanobe A, Kobayashi I, Takahashi K, Ui M, Katada T. Direct interactions of mastoparan and compound 48/80 with GTP-binding proteins. J Biochem. 1991; 109: 184-189.

26. Tanaka T, Kohno T, Kinoshita S, Mukai H, Itoh H, Ohya M, et al. Alpha helix content of $G$ protein alpha subunit is 
decreased upon activation by receptor mimetics. J Biol Chem 1998; 273: 3247-3252, doi: 10.1074/jbc.273.6.3247.

27. Takano H, Liu W, Zhao Z, Cui S, Zhang W, Shibamoto T. N $^{\omega}$ nitro-L-arginine methyl ester, but not methylene blue, attenuates anaphylactic hypotension in anesthetized mice. J Pharmacol Sci 2007; 104: 212-217, doi: 10.1254/jphs. FP0070169.

28. Chakraborty S, Kar N, Kumari L, De A, Bera T. Inhibitory effect of a new orally active cedrol-loaded nanostructured lipid carrier on compound 48/80-induced mast cell degranulation and anaphylactic shock in mice. Int $J$ Nanomedicine 2017; 12: 4849-4868, doi: 10.2147/IJN.S132114.

29. Fu YS, Kuo SY, Lin HY, Chen CL, Huang SY, Wen ZH, et al. Pretreatment with Evans blue, a stimulator of $\mathrm{BK}(\mathrm{Ca})$ channels, inhibits compound 48/80-induced shock, systemic inflammation, and mast cell degranulation in the rat. Histochem Cell Biol 2015; 144: 237-247, doi: 10.1007/ s00418-015-1332-4.

30. Xu Y, Kang T, Dou D, Kuang $H$. The evaluation and optimization of animal model for anaphylactoid reaction induced by injections. Asian Pac J Allergy Immunol 2015; 33: 330-338.

31. Kim SH, Shin TY. Amomum xanthiodes inhibits mast cellmediated allergic reactions through the inhibition of histamine release and inflammatory cytokine production. Exp Biol Med 2005; 230: 681-687, doi: 10.1177/15353702052 3000911.

32. Oliveira Neto AM, Duarte NM, Vicente WV, Viaro F, Evora PR. Methylene blue: an effective treatment for contrast medium-induced anaphylaxis. Med Sci Monit 2003; 9: CS102-CS106.

33. Amir S, English AM. An inhibitor of nitric oxide production, $\mathrm{N}^{\omega}$-nitro-L-arginine-methyl ester, improves survival in anaphylactic shock. Eur J Pharmacol 1991; 203: 125-127, doi: 10.1016/0014-2999(91)90800-6.

34. Evora PR, Simon MR. Role of nitric oxide production in anaphylaxis and its relevance for the treatment of anaphylactic hypotension with methylene blue. Ann Allergy Asthma Immunol 2007; 99: 306-313, doi: 10.1016/S1081-1206(10) 60545-5.

35. Cauwels A, Janssen B, Buys E, Sips P, Brouckaert P. Anaphylactic shock depends on PI3K and eNOS-derived NO. J Clin Invest 2006; 116: 2244-2251.

36. Ng TY, Datta TD, Kirimli BI. Reaction to indigo carmine. J Urol 1976; 116: 132-133, doi: 10.1016/S0022-5347(17) 58715-7.

37. Burleson RL, Kasulke R, Jones DB, Marbarger P, DeRito J, DeVoe $C$. The effect of dyes used to evaluate the in situ, exvivo, and perfused kidney. Invest Urol 1981; 19: 165-168.

38. Jeffords DL, Lange PH, DeWolf WC. Severe hypertensive reaction to indigo carmine. Urology 1977; 9: 180-181, doi: 10.1016/0090-4295(77)90192-3.

39. Shir Y, Raja SN. Indigo carmine-induced severe hypotension in patients undergoing radical prostatectomy. Anesthesiology 1993; 79: 378-381, doi: 10.1097/00000542-19930800000024.

40. Nguyen AC, Kost E, Framstad M. Indigo carmine-induced severe hypotension. Anesth Analg 1998; 87: 1194-1195. 